\title{
HEGEL E A DIALÉTICA COMO MOVIMENTO NECESSÁRIO NO INTERIOR DA ARTE
}

\author{
Paula Regina Farias dos Santos ${ }^{1}$
}

\begin{abstract}
RESUMO: Este trabalho tem como função fazer uma análise sobre o percurso dialético promovido pela arte no interior da estética hegeliana. Desse modo, faz-se necessário acrescentar o papel primordial da história da arte, do movimento histórico desta como manifestação cultural de um povo, na qual as diversas formas de obra de arte representam a tentativa de adequar o conteúdo espiritual à forma material. Hegel, dessa forma, entende a unidade histórica, portanto dialética, como unidade da ideia. Além do mais, o filósofo acredita que o conhecimento que o espírito possui de si mesmo só é possível a partir da sua efetividade entendida como verdade. A análise tem como principal recurso Os cursos de Estética, nos quais Hegel expõe de maneira minuciosa a trajetória do espírito, desde o mundo prosaico até sua elevação e representação através do conteúdo artístico.
\end{abstract}

Palavras-chave: Hegel, Dialética; Movimento; Arte

\begin{abstract}
This work has the function to do an analysis on the art promoted by the dialectical within the Hegelian aesthetics. Thus, it is necessary to add the vital role of art history, the history of this movement as a cultural manifestation of a people, in which the various forms of artwork represent the attempt to bring the spiritual content of the material form. Hegel thus considers the historical unity, therefore the dialectic, as the unit of the idea. Moreover, the philosopher believes that the knowledge that the spirit has of itself is only possible from its effectiveness as a truth understood. The analysis has as main courses Aesthetic appeal, in which Hegel explains in a minute the trajectory of the spirit, from the workaday world until his elevation and representation through artistic content.
\end{abstract}

Key-words: Hegel, Dialectic; Movement; Art

Hegel definia a dialética como desenvolvimento do conceito a partir de si mesmo, num avanço constante que não consistia apenas na afirmação de relações de diferença, mas no entendimento do universal presente nas coisas, mais propriamente no seu vir-a-ser.

\footnotetext{
${ }^{1}$ Graduada em Filosofia pela Universidade Estadual de Santa Cruz - UESC. Monografia de conclusão de curso transformada em artigo sob orientação e supervisão da Prof ${ }^{a}$. Dr. Carla Milani Damião.
} 
Para o filósofo alemão, à arte e somente a esta cabe a representação sensível do espírito, e sua ideal manifestação consiste na questão de adequar o conteúdo à forma sensível que mais manifeste o espiritual a que se destina.

Através do movimento dialético presente nas diversas representações, no movimento histórico do percurso em que cada forma de arte aparece, é possível perceber que, cada forma corresponde a uma tentativa de manifestar o espírito em sua liberdade, partindo de determinada cultura, sua forma de pensar e conceber o mundo, enfim, de realizar, no plano do concreto, o absoluto.

Segundo Gérard Brás (2001), no entanto, ao realizar uma análise das diversas formas de arte e suas representações individuais, é necessário, antes de tudo, não concebê-las como realizações de ordem cronológica, mas lógica. É preciso pensar que o ideal de beleza é passível de ser realizado através dos diversos modos artísticos, não como uma sucessão temporal no qual um período se encerra e outro começa, mas, onde o belo ideal deva ser alcançado através da adequação entre ideia e conteúdo sensível, em cada cultura. E isso se dá a partir de uma análise da história da arte, não como factual e positivista, mas filosófico-dialética, de como a arte é representada pelos diversos povos.

Hegel, ao conceber a unidade histórica, afirma-a concebendo também a ideia. Assim, pode-se dizer que ideia e movimento histórico são uma e a mesma coisa, posto que a ideia se realiza no percurso promovido pela história, tornando-se real e efetiva. Pensando desta forma, é possível afirmar que o conceito hegeliano de ideia não é aquele entendido pela filosofia antiga platônica ou com base na filosofia de Platão, que a via como algo fixo, mas, que diz respeito a um vir-a-ser constante, às mudanças referentes à efetividade e realidade das coisas, e que fazem parte de sua totalidade.

Desse modo, as diferentes representações artísticas, mesmo que imprecisas são necessárias, pois, tentam atingir o ideal de beleza produzido pela ideia:

Temos na arte um particular modo de manifestação do espírito, dizemos que a arte é uma das formas de manifestação porque o espírito, para se realizar, 
pode servir-se de múltiplas formas. O modo particular de manifestação do espírito constitui essencialmente um resultado. ${ }^{2}$

Assim, a arte é o resultado do movimento do espírito que desemboca no modo sensível, da tentativa de manifestação do absoluto, posto que a filosofia e a religião só o realizam no modo da abstração e da reflexão.

No percurso histórico, a verdade é o conhecimento que o espírito concebe de si mesmo, e em seu movimento se faz realidade como efetividade. Assim, é importante notar que é impossível à história da arte caminhar sem ser diretamente relacionada à manifestação do espírito além do aspecto cultural, e esta atribuição proporcionada por Hegel retira as manifestações artísticas do estado puramente histórico e passa a classificá-las através das determinações e representações da arte de forma individual, independentemente do modo temporal em que elas aparecem.

\section{A necessidade da arte}

Para Brás, a manifestação artística se desenvolve ao longo da história e desta faz parte, mas, não pode se limitar ao entendimento de que a história a encerra como importância representativa. Ao contrário, Hegel não descarta a importância da história para o fato da arte se tornar conhecida e classificada. No entanto, a historicidade da arte pura e simples coloca-a num patamar puramente classificatório, relegando-a a uma esfera temporal e como que separada das outras formas referidas.

Ao retirar a arte da esfera puramente histórica, o filósofo alemão re-estabelece a importância da representação artística ao âmbito filosófico, o da filosofia da arte e a reintegra como parte do absoluto e como sua representação, unindo a reflexão sobre sua significação à análise das formas apresentadas.

Conforme Márcia Gonçalves (2002), para o filósofo alemão, pode-se afirmar que a importância da arte está no fato de que, como participante do absoluto, ela traz ao homem, como um reflexo deste no espelho, uma ideia de sua própria cultura e um

\footnotetext{
${ }^{2}$ G. W. F. HEGEL, Cursos de Estética III, p. 9.
} 
retorno do espírito para si, no qual este se torna ciente de sua essência e do entendimento sobre si mesmo. No entanto, a arte não proporcionará a superação mediada pelo pensamento do mundo prosaico e do estranhamento do homem com relação a este, e sua elevação, com relação à natureza, não o retira do seu estado de selvageria presente no âmbito da natureza, em outras palavras, não tem a função de mudança moral ou transformadora.

Hegel não relaciona o interesse espiritual da arte e sua representação em conformidade com uma educação para a transformação ou manutenção de uma realidade social vigente. Ao contrário, a questão da recepção artística é vista num âmbito de unidade cultural, portanto, do universal que diz respeito à capacidade do indivíduo em percebê-la em vista das potencialidades presentes na razão.

Mesmo que a arte venha a suavizar os costumes e a barbárie presentes na natureza, não é o seu propósito exercer a função da religião e moral:

Dizer que a função da arte é agradar, ser origem de prazer, corresponde a determinar um fim naturalmente acidental que não podia ser o da arte. A religião, os costumes, a moral constituem já objetos existentes em si mesmos, e quanto mais a arte contribuir para favorecer as aspirações religiosas e as tendências morais, e para suavizar os costumes, tanto mais elevado será o fim atingido. $^{3}$

A religião, a política e a moral seriam figuras da eticidade, com suas funções próprias e independentes, não conformando a estas a finalidade de pertencerem à função exercida pela arte, analisa. A arte, no entanto, pode contribuir para que estas noções sejam atingidas com mais facilidade, mas não corresponde à sua essência e atividade.

A tentativa de atingir o ideal através da criação artística diz respeito ao movimento do espírito, movimento este que se revela em sua expressão sensível, que se faz produto da criação humana e não é resultado de uma observação da natureza e do que aparentemente é belo e presente nesta.

Para Hegel, só é pertencente à filosofia da arte o que é resultado da consecução artística e não o que pertence à natureza ou ao mundo prosaico, ou seja, só pode ser

\footnotetext{
${ }^{3}$ Ibidem, p. 38.
} 
considerado como belo aquilo que já se elevou para além da brutalidade presente no mundo natural, e esta em sua pura aparência dita como bela não é nada mais que um retorno da própria subjetividade humana que a reconhece como tal, mas não pode classificá-la como pertencente ao belo propriamente dito.

O espírito, em seu movimento, assume o caráter de seu ser-outro, e à arte cabe esta atividade funcional de, através de sua representação, tornar possível o reconhecimento do espírito para si, observa Márcia Gonçalves:

Quero afirmar que - em termos hegelianos - a obra de arte espelha a espiritualidade que se quer e que começa a se saber absoluta. Isto significa que a arte constitui para Hegel a primeira (não a única, tampouco a mais elevada) etapa de libertação, de sua elevação acima das relações contingentes e não-livres do mundo finito, posto que ela é a primeira forma espiritual efetiva de produção de si mesmo. ${ }^{4}$

O trabalho artístico constitui para Hegel uma atividade racional, dado o caráter de elevação do espírito, que eleva o homem do mundo prosaico para a racionalidade, devido ao reconhecimento deste como ser racional e provido de entendimento.

A arte, desse modo é absoluta, porque pode ser compreendida como reflexo da espiritualidade. Por meio da arte, o espírito se liberta, eleva-se e se realiza como efetividade a partir da criação. No entanto, não se trata da forma mais elevada de representação do espírito, mas, o que dá início à sua manifestação.

Ao tratar da arte, Hegel procura ultrapassar os limites deixados anteriormente por outros filósofos, no que se refere à oposição entre subjetividade e objetividade, ideia e representação concreta, por exemplo, as ideias de estética kantiana, que resolveriam o problema apenas no âmbito subjetivo.

Portanto, parte da subjetividade para suprir um conflito entre espiritualidade e ente sensível, põe no campo moral e a priori aquilo, que deve ser unido, a subjetividade e o concreto.

\footnotetext{
${ }^{4}$ M. C. F. GONÇALVES, O Belo e o Destino, p. 61.
} 
Schelling acreditava na superação e libertação do mundo prosaico através da arte e, pode-se dizer que mesmo Hegel em seus fundamentos sobre filosofia da arte já presumia que a representação artística era capaz de livrar o homem do estado de natureza e de forma subsequente, da brutalidade e selvageria decorrentes desta.

A intuição, para Hegel, propicia a mediação do conhecimento pela arte, e faz reconhecer no homem uma dicotomia da espiritualidade infinita que existe em si mesmo através da representação artística e sua essência divina, ao mesmo tempo, a manifestação sensível que revela sua finitude, portanto o corpóreo e humano:

O reconhecimento mediado pela arte é apenas intuitivo e, portanto, não implica ainda o superar, mas apenas o apresentar a duplicação interna que caracteriza a própria natureza humana. $\mathrm{O}$ homem reconhece sua espiritualidade infinita no conteúdo divino da arte; sua natureza física finita, ele a reconhece em sua forma sensível. A unidade harmônica de ambos os termos realiza a beleza como idealização do sensível. ${ }^{5}$

Desse modo, a beleza tomada como ideal é realizada através da junção e unidade destes dois opostos anteriormente citados, posto que para Hegel, a consciênciade-si só pode ser atingida, se elevado à interioridade e exterioridade pelo espírito.

No entanto, não é correto afirmar que seja proibido à representação artística conter elementos do mundo prosaico. Apesar da idealização na arte, os conteúdos mundanos podem ser representados nesta, porém, a partir do caráter de mediação, ou seja, de um modo de elevação desta representação, a partir de sua manifestação na obra de arte, como que modificada pela própria obra, seja na pintura, na escultura ou na arquitetura.

Assim, o mundo prosaico não é simplesmente negado como possível de ser expresso na arte, mas, há a negação da negatividade abstrata, do mundo e do estranhamento provocado por este. Dessa forma, ao tomar objetos concretos, a arte os transforma-os em algo subjetivo, em algo pertencente ao espírito.

O que é interessante notar é que há uma idealização do natural e, embora o filósofo idealista conceba uma unidade entre espírito e natureza, há uma sobreposição

\footnotetext{
${ }^{5}$ Ibidem, p. 62.
} 
do aspecto espiritual sobre o prosaico, na qual o primeiro sempre acaba transpondo o material e o natural, perpassando-o e mostrando toda sua liberdade.

Através da análise das figuras históricas, é promovida a compreensão de como se dá a idealização do natural para o espiritual e se esta elevação é realmente necessária e adequada

Analisando as formas de arte propostas pela divisão hegeliana é possível observar o nível de elevação e de idealização que estas alcançaram, e como cada uma destas demonstra que, a representação do divino é recorrência necessária na história dos povos e o aspecto religioso está sempre presente em suas manifestações, concretizando a ideia suscitada como conteúdo em uma forma utilizada para tornar possível sua sensibilidade.

Para cada período histórico, Hegel determina uma forma representativa, e as obras e formas particulares se articulam com as três formas de arte estabelecidas pelo filósofo: arte Simbólica, arte Clássica e arte Romântica. Assim, o filósofo alemão atribui o mesmo significado que pode ser alcançado da arquitetura com sua manifestação através da matéria pesada, à música que se faz representar apenas através da vibração sonora. Estas duas constituem formas de representação do espírito.

Tratando de uma forma mais direta, a arquitetura pode ser facilmente atribuída à forma Simbólica, isso porque, sua criação está inicialmente associada a uma delimitação territorial, algo que teria o propósito de ressaltar o caráter da cidade ou do social suscitado pelas civilizações.

Assim, o espaço natural é dividido com as obras arquitetônicas, uma oposição já aparente entre natureza e construção humana. O espírito mostra todo o seu peso, o que demonstra já uma inadequação entre ideia e manifestação material, desse modo, o espiritual e o natural já se opõem, pois, o último é superado devido à incapacidade de adequar a forma ao conteúdo.

Se a escultura já é, por definição conceitual, Simbólica, a escultura podemos definir como Clássica, e as demais artes, como a pintura e a música, podemos definir como Romântica, afirma Bras: 
A escultura é eminentemente clássica porque nela se manifesta da melhor maneira, em toda sua independência , a beleza formal do corpo humano.Ora, a figura humana é justamente esse ser natural, sensível, em que o Espírito encontra sua expressão justa. ${ }^{6}$

A genialidade dos gregos permitiu que o espiritual se adequasse de maneira harmônica ao corpo humano. Este pode se expressar de uma maneira equilibrada na figura natural, sendo que são justapostas as características humanas à interioridade da alma, fato que nos faz perceber o homem como unidade capaz de representar o humano e o divino. No entanto, a estátua grega possui uma serenidade advinda da forma humana, que é produto da subjetividade e é própria à estátua, que deixa intrínseco o espiritual sem uma relação exterior com o mundo.

A pintura já está no âmbito de outro tipo de representação espiritual, já que esta se afasta do natural. Ela se sustenta inteiramente na interioridade, onde o espiritual impera não mais se manifestando na concretude. Podemos considerá-la já como arte Romântica e como característica principal a liberdade de expressão, determinada como pertencente a um determinado período e a um tipo de pensamento:

O princípio essencial da pintura ,como já disse, é constituído pela subjetividade interna e vivente, com seus sentimentos, representações e ações tendo por objetos tudo o que existe e desce do céu à terra, com a multiplicidade das suas situações e das suas manifestações exteriores e corporais, e é por esta razão que a arte romântica ou cristã encontra a sua realização mais adequada na pintura.

As cores aparecem como marco essencial para a determinação da interioridade, onde a vida se torna ainda mais representada, posto que, as cores e sua junção se referem à vitalidade, ao movimento da vida e de sua liberdade. No entanto, por representar o natural, mais claramente o mundo prosaico, a pintura demonstra desde cedo a incapacidade de tratar das coisas novas, prende-se ao mundano de uma forma que o que passa a se destacar é somente o jogo de cores.

\footnotetext{
${ }^{6}$ G. BRAS, Hegel e a Arte, p. 90.

${ }^{7}$ G. W. F. HEGEL, Cursos de Estética III, p.127.
} 
Na música, não há espaço, não há uma extensão concreta em que se possa visualizar a obra como acabada, mas, toda sua apreensão é possível a partir da vibração sonora, e a extensão dá lugar ao tempo de execução de sua sonoridade.

Após ser ouvida, só ficará presente na alma, e no sentimento que nos suscita, está presente puramente na interioridade e por isso é mais fácil de penetrar na alma e em nossa subjetividade:

É pois, por excelência, a arte da interioridade subjetiva capaz de mergulhar no coração da alma .É em sua natureza formal que encontra essa capacidade: não tendo o som nenhuma existência independente, nada resta dele após sua emissão além do sentimento interiorizado pelo ouvinte. ${ }^{8}$

É a arte subjetiva por excelência. O espírito parece ter se exteriorizado em forma de som e retornado a si após a execução de uma melodia.

A música tem a capacidade de se tornar independente do exterior para manifestar-se, precisa do sentido da audição para ser contemplada e com isso é mais ideal do que a pintura, pois, nesta está presente apenas o caráter subjetivo e sobre ela não há e não pode haver qualquer opressão do objeto.

Dessa forma a música subsiste livremente em sua execução, ficando o sentido da audição apenas responsável por captar o resultado da vibração resultante de sua emissão.

De uma forma singular, a arte, ao contrário da história, não é ultrapassada através das formas de representações atuais, ou melhor, pelo caráter seqüencial, como esta última é superada pelos fatos históricos mais recentes. Dessa forma, cada momento, cada estilo e maneira de representar a arte tenta exprimir o absoluto, onde os momentos anteriores não deixam de ter a sua importância, e isso se trata de uma visão filosófica, no que diz respeito à história da arte e sua necessidade. A estética, pela sua função, coloca a arte e suas formas diante de nós de uma maneira ordenada, e não cronológica, restaurando a significação da representação artística pela sua capacidade de adequação

\footnotetext{
${ }^{8}$ G. BRAS, Hegel e a Arte, p. 93.
} 
entre a ideia e a sua manifestação objetiva, sendo esta tomada pelo seu caráter formal e não de ordem temporal.

Cada modo, cada maneira de realização artística é uma tentativa de manifestação no concreto, no material, realizando a verdade em sensibilidade. Pode-se entender, deste modo, que em cada figura particular, trata-se de representações individualizadas das diferenças contidas no conceito de belo, e cada uma destas tenta atingir este conceito da maneira mais perfeita.

Essa capacidade do conceito de belo em se fazer representar de diversas maneiras pode ser mais bem compreendida através da forma de divisão estabelecida por Hegel, nas formas da arte Simbólica, Clássica e Romântica, nas quais o material é unido ao espiritual para que este possa se tornar passível de ser apreendido pelos sentidos. Mas, para compreender como se dá essa divisão, é necessário pensar cada uma, não como que situada anteriormente ou de forma posterior à outra, já que podemos encontrar algumas formas de arte dentro desta classificação presentes no mesmo período histórico. Não se deve pensar que cada forma de arte existiu em um período da história definido, separado dos outros, e que a ordem de sua nomeação se deva isso.

É necessário, antes de tudo, entender que a ideia de formas de arte se baseia na possibilidade de o belo se fazer representar. Dessa maneira, o filósofo alemão procura uma definição teórica para a história da arte, ao dividi-la nestas três formas. Se levarmos em consideração a arte muçulmana, forma de arte oriental, veremos que ela é contemporânea da arte clássica grega, apresentando algumas obras que coincidem com o período em que a arte grega é produzida. O próprio Hegel exalta o caráter de simultaneidade das duas formas de arte.

No movimento dialético de superação da arte estão a filosofia e a religião, e, num processo teleológico, a arte caminha para ser superada por estas duas formas do absoluto, constituindo um processo no qual a origem e o fim resultam em uma unidade necessária.

A unidade entre o universal e o particular é, para Hegel, possibilitada apenas a partir do âmbito filosófico e não pode ser compreendido pela intuição. $\mathrm{O}$ desenvolvimento histórico desestrutura a unidade antes mencionada, no entanto, já 
demonstra o ideal em sua realização efetiva. Desse modo, a dupla natureza da arte mostra a contradição existente no interior da arte, contradição que caracteriza o destino humano. A arte se encontra, pois, limitada, o que é demonstrado no movimento histórico coincidentemente se iguala ao destino humano em sua finitude.

Mas a arte não é capaz de transpor e superar essa finitude própria de si, pois, a esta cabe a elevação espiritual e uma reflexão sobre seu movimento histórico, tarefa essencial da estética que a pensa não como algo destinado ao fim, mas como uma contínua sucessão de representações, que tendem à evolução de sua forma de representar.

Sua característica fundamental é a liberdade e a necessidade de expressão, mas a ela não cabe a função de libertar, ou seja, embora esteja o espírito voltado para a manifestação livre, este não tem um propósito de, ao primeiro momento, retirar o indivíduo de uma condição ideológica qualquer ou de mantê-lo dentro de uma visão política ou ideológica qualquer.

Embora Hegel parta do conceito de ideal, este conceito, que tem como base a concretização de sua ideia, não permanece no plano metafísico, mas, justifica-se na tentativa de manifestar-se como beleza que pode ser passível de sensibilidade, num conjunto caracterizado pelo meio cultural de cada povo.

Hegel tem o intuito de justapor duas formas de entender o belo, ambas antagônicas, tal qual a visão platônica e a aristotélica que se fixavam em entendimentos totalmente diferentes.

Se partirmos do conceito utilizado por Platão, veremos que ele se fundamenta na ideia de beleza como verdade, voltada para a moral ou o bem, no entanto, Aristóteles a concebia como movimento histórico, e sua forma empírica é manifesta na sensibilidade, ressalta Gonçalves:

Hegel esclarece este duplo componente metafísico e empírico a partir da necessidade de conciliar dois métodos clássicos de compreender a estética, cujas origens se situam na filosofia de Platão e na de Aristóteles. O primeiro 
método tem como base o conceito metafísico de belo, que serve tanto como parâmetro de verdade ou como fim último do conhecimento dialético. ${ }^{9}$

O filósofo alemão, embora conserve o caráter de universalidade do ideal de beleza platônico, eleva seu entendimento de belo para além da abstração, recorrendo à manifestação empírica e à explicação histórica de seu desenvolvimento constante.

Desse modo, se a arte permanecer tão somente no âmbito de sua aparição concreta, para Hegel, ela permanecerá no campo da abstração, e nada mais significará que uma sucessão de obras que se apresentam em ordem cronológica, pois, embora o filósofo defenda a importância da historicidade da arte, ressalta a problemática de não se restringir sua importância apenas a esta sucessão classificatória, mas que deve recorrer ao âmbito filosófico.

Assim como a filosofia em Hegel não fica apenas no aspecto da abstração, mas deve procurar sua relação com a história e esta como razão a realiza, a arte também não deve se limitar ao âmbito puramente da reflexão, mas deve partir da essência para sua realização como belo através da obra propriamente dita.

Hegel une, através da criação artística, o belo ideal da teoria platônica à ideia de beleza em sua realização concreta e empírica aristotélica, e tenta preencher a oposição anteriormente deixada pelos filósofos idealistas entre subjetividade espiritual e objetividade.

Bibliografia

ABBAGNANO, Nicola. Dicionário de Filosofia. São Paulo: Ed. Mestre Jou, 1970.

BRAS, Gérard. Hegel e a Arte. Rio de Janeiro: Jorge Zahar Editor, 2001.

\footnotetext{
${ }^{9}$ M. C. F. GONÇALVES, O Belo e o Destino, p. 69.
} 
GONÇALVES, Márcia Cristina F. O Belo e o Destino. -Uma Introdução à Filosofia de Hegel. São Paulo: Edições Loyola, 2002.

HEGEL, Georg W. Friedrich. Cursos de Estética. Volume III. São Paulo: Edusp, 2002. 